\title{
A study on the structure of the convective atmosphere over the Bay of Bengal during BOBMEX-99
}

\author{
U C Mohantr*, N V Sam, S Das ${ }^{1}$, A N V Satyanarayana \\ Centre for Atmospheric Sciences, Indian Institute of Technology, Delhi, New Delhi, India. \\ ${ }^{1}$ National Centre for Medium Range Weather Forecasting, Lodhi Road, New Delhi, India. \\ *e-mail: mohanty@cas.iitd.ernet.in
}

\begin{abstract}
Convective activity is one of the major processes in the atmosphere influencing the local and largescale weather in the tropics. The latent heat released by the cumulus cloud is known to drive monsoon circulation, which on the other hand supplies the moisture that maintains the cumulus clouds. An investigation is carried out on the convective structure of the atmosphere during active and suppressed periods of convection using data sets obtained from the Bay of Bengal and Monsoon Experiment (BOBMEX). The cumulus convection though being a small-scale phenomenon, still influences its embedding environment by interaction through various scales. This study shows the variation in the kinematic and convective parameters during the transition from suppressed to active periods of convection. Convergence in the lower levels and strong upward vertical velocity, significant during active convection are associated with the formation of monsoon depressions. The apparent heat source due to latent heat release and the vertical transport of the eddy heat by cumulus convection, and the apparent moisture sink due to net condensation and vertical divergence of the eddy transport of moisture, are estimated through residuals of the thermodynamic equation and examined in relation to monsoon activity during BOBMEX.
\end{abstract}

\section{Introduction}

Deep and intense cumulus convection can have an important effect on the dynamics and energetics of large-scale atmospheric systems, because of the large magnitudes of the energy transformations associated with changes of phase of water in precipitating cumulus clouds as well as the strong updrafts and downdrafts which often extend through the troposphere. The importance of deep cumulus clouds in the heat balance of the tropical atmosphere was first pointed out by Riehl and Malkus (1958). They depicted that deep cumulus clouds can carry the released latent heat of condensation to the upper troposphere where the local vertical gradient of moist static energy is positive. The tropical cyclone is perhaps the best example of a mesoscale atmospheric system that owes its existence to the release of latent heat in cumulus convection (Riehl and Malkus 1961; Yanai $1961 \mathrm{a}, \mathrm{b}$ ). The first theoretical formulation of the cumulus macro-motion coupling through boundary layer convergence was made by Charney and Eliassen (1964) and Ooyama (1964, 1969a), in their attempts to explain the growth of tropical cyclones, where they introduced the concept of conditional instability of the second kind (CISK).

Studies of tropical convective systems over Marshall Islands in the Pacific Ocean and over the eastern Atlantic Ocean during GARP Atlantic Tropical Experiment (GATE) has indicated a strong control of cumulus convection, and efforts are still on to clarify the nature of the interaction between small-scale cumulus convection and the large-scale circulation of the troposphere. Much attention is given to the diagnostic study of the interaction processes. Yanai et al (1973) devel-

Keywords. Convection; monsoon depression; Bay of Bengal; BOBMEX. 
oped a diagnostic method for the determination of the bulk or averaged profiles of clusters of cumulus clouds from the observations of large-scale meteorological variables. Various other methods, developed by Ogura and Cho (1973) and Nitta (1975), enabled the study of spectral distribution of cumulus mass flux, for clusters of cumulus clouds to be diagnosed from large-scale variables. In these studies, the cumulus cloud has been modeled as a one-dimensional, steady state entraining plume updraft.

It is evident that a large amount of latent heat is liberated in cumulus clouds and the released heat is transported upwards, but how this heat is utilized in warming the large-scale environment, is not so obvious. Therefore it becomes very necessary to have a better understanding of this physical process to improve cumulus parameterization. The prime objective of this study is to understand the convective structure of the atmosphere, both in convectively active and suppressed episodes observed during BOBMEX-99. BOBMEX, an observational program under the ICRP (Indian Climate Research Program) over the Bay of Bengal was conducted during JulyAugust 1999. ICRP gives a major thrust on monsoon variability on various timescales ranging from subseasonal-interannual and decadal (DST 1996). Most of the rainfall observed during the monsoon period over the Indo-Gangetic plain occurs mostly due to lows and monsoon depressions originating over the waters that move on to the landmasses. The genesis of monsoon depressions are very high over the Bay of Bengal (Rao 1976). Bhat et al (2001) stated that the distribution of the summer monsoon rainfall during June to September over the Indian region is linked to the variation of convective activities over the Bay of Bengal. The special observation programme BOBMEX, therefore, paved the way in collecting critical data on the subseasonal variation of important variables of the atmosphere, ocean and their interface to get a deeper insight into some of the processes that govern the variability of organized convection over the Bay of Bengal (Bhat et al 2001).

Very high-resolution upper air data were obtained from Vaisala sondes during this experiment that was used to study the variability of organized convection over the Bay of Bengal. It is for the first time that such high-resolution upper air data were obtained over the Bay of Bengal. These observations show that the magnitudes of the convective available potential energy (CAPE) and the convective inhibition energy were comparable to those for the atmosphere over the west Pacific warm pool, where CAPE decreased by $2-3 \mathrm{kJkg}^{-1}$, following convection and recovered in a time period of 1-2 days (Bhat et al 2001). The kinematic and convective budgets of an environment during BOBMEX-99 over a scale of 100-1000 km are grouped in B-Scale (GARP). For the convectively active and suppressed periods the profiles of kinematic parameters viz., mean zonal and meridional wind; the vertical velocity and its daily variation and profiles of convective parameters (dry, moist and saturation moist static energy; apparent heat source and moisture sink, etc) have been computed.

\section{Data and synoptic condition}

Two different sets of data consisting of six hourly (00, 06, 12, 18 GMT) obtained onboard ORV Sagar Kanya and from land stations viz., Bhubaneshwar and Calcutta are used in this study. Each set is a period of three days. In the first set ( $\mathrm{I}^{\text {st }}$ period: 13th-15th August 1999) ORV Sagar Kanya was stationed approximately at $17.54^{\circ} \mathrm{N}, 89.02^{\circ} \mathrm{E}$. The observations taken over land stations, Bhubaneshwar and Calcutta are respectively at $20.1^{\circ} \mathrm{N}, 85.1^{\circ} \mathrm{E}$ and $23.4^{\circ} \mathrm{N}, 86.5^{\circ} \mathrm{E}$. Figure 1 shows the position of ship and land stations during the period. The three observation points together formed a triangular column of atmosphere representing the Bscale as defined during GATE. The period (13th15th August 1999) is termed as the convectively active period based on observed rainfall and synoptic situations. The $850 \mathrm{mb}$ wind analysis of NCMRWF (National Centre for Medium Range Weather Forecasting) at 00 UTC show strong westerlies in the convectively active regime. On the 15th (figure 2a), a well-marked low (north Bay) is noticed over land near Bhubaneshwar. Also rain (figure 3a) amounting to approximately $120 \mathrm{~mm}$ is observed onboard ORV Sagar Kanya on the 15th. This rainfall is measured using the precipitation gauge from R. M. Young (U.S.A) that was placed in an open space on the upper deck of the ship. In this period the sky (figure 3c) is also found to be almost all the time overcast ( 8 octa). Figure 4 ( $\mathrm{a}$ and $\mathrm{b}$ ) shows the observed rainfall at Bhubaneshwar (max. $51 \mathrm{~mm}$ on 15th August 1999) and Calcutta (max. $35 \mathrm{~mm}$ on 14th August 1999) respectively. The sky is also noticed to be partially cloudy (figure 4c and d) during this period. Satellite pictures show more of stratus clouds over Bhubaneshwar during this period. During the IInd phase of observations (22nd-24th August 1999), ORV Sagar Kanya was approximately located at $17.59^{\circ} \mathrm{N}, 88.84^{\circ} \mathrm{E}$ (figure 1). The NCMRWF $850 \mathrm{mb}$ wind analysis during this period does not show strong westerlies as seen in the case of the convectively active period. Although, a circulation pattern is seen to be developing near the head of 


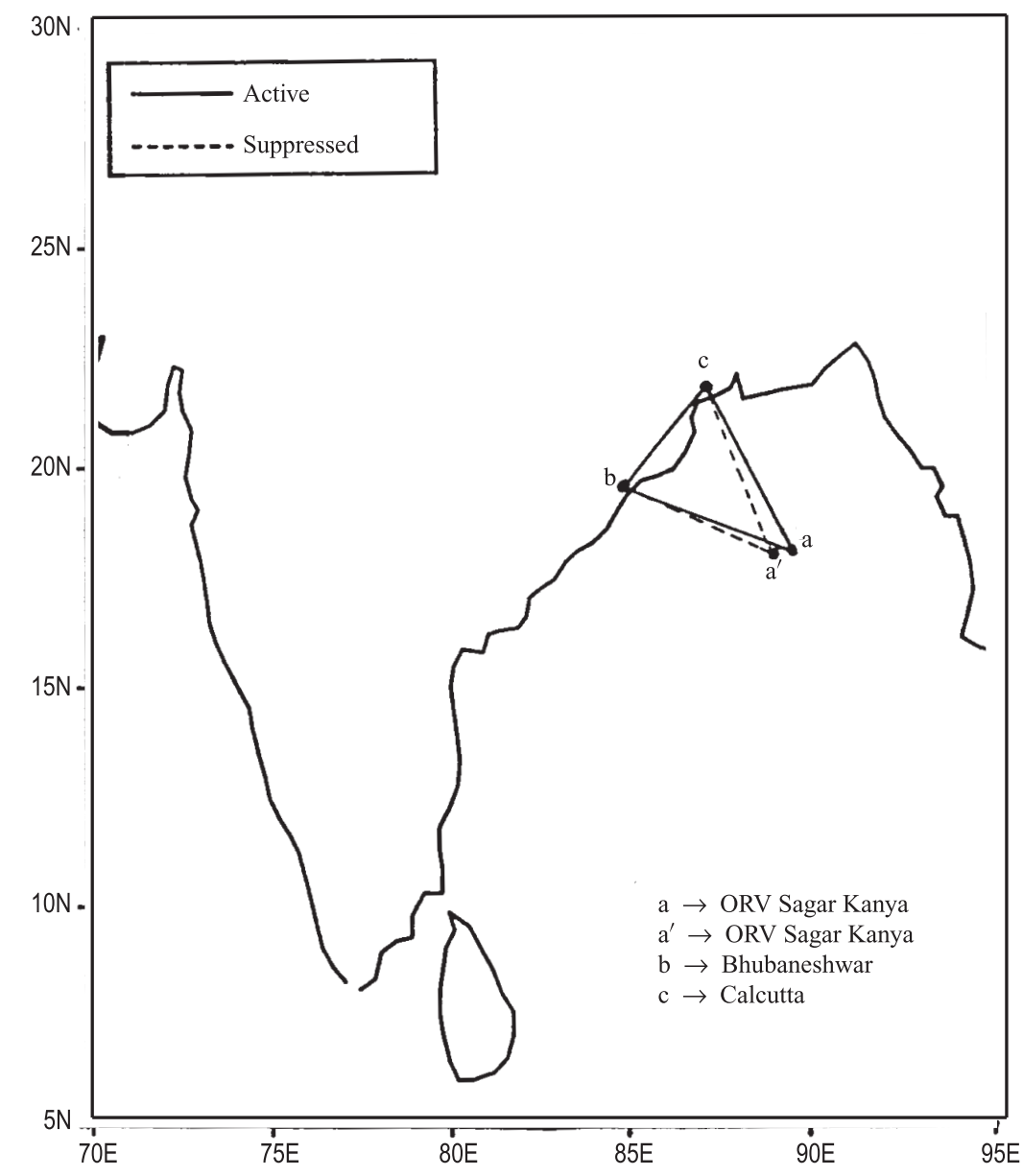

Figure 1. Stationary position of ORV Sagar Kanya and the two land stations Bhubaneswar and Calcutta forming triangles during active and suppressed convection periods respectively.

the north Bay (figure 2b), the ship was outside this region. Therefore, the effect of the weak circulation pattern is ineffective in making a major influence that could lead to convective activity. Thus, the period (22nd-24th August 1999) is termed as convectively suppressed for this study. Less than $20 \mathrm{~mm}$ rainfall is observed on $22 \mathrm{nd}$ (figure $3 \mathrm{~b}$ ), onboard ORV Sagar Kanya, while no rainfall is observed during the other two days (23rd and 24th August 1999). The sky is found to be less cloudy (figure $3 \mathrm{~d}$ ) and no rainfall is observed at Bhubaneshwar and Calcutta during this period. A detailed description of the synoptic situation during both these periods is given in Sam et al (2003).

The triangle (figure 1) with continuous lines represents the active regime and that with dashed lines, the suppressed regime. This study uses an approach to obtain the average structure of a cloud cluster and its interaction with the environment. The high degree of organization of convective clouds into clusters during monsoons suggested their likely association with large-scale wave disturbances. Chang (1970) had presented the evidence of systematic westward propagation of the cloud clusters. We now have several working hypotheses concerning the origin of the waves and their interaction with organized cumulus convection. Thus the so-called wave and cloud-cluster interaction has become important in the understanding of tropical meteorology. The idea is to calculate both, the convective and the kinematic parameters at the centre of the triangle. Highresolution upper air data obtained during BOBMEX was a real boon for this study. The data sets were processed for internal consistency. A linear interpolation technique was used to interpolate some of the data at regular intervals of $50 \mathrm{mb}$ from 1000 to $100 \mathrm{mb}$. Missing observations were replaced by fitting a linear regression equation in time and space. The horizontal derivatives, viz., $\nabla \cdot V, \nabla X V$, etc, are obtained from regression coefficients, as explained by Mohanty and Das (1986). 


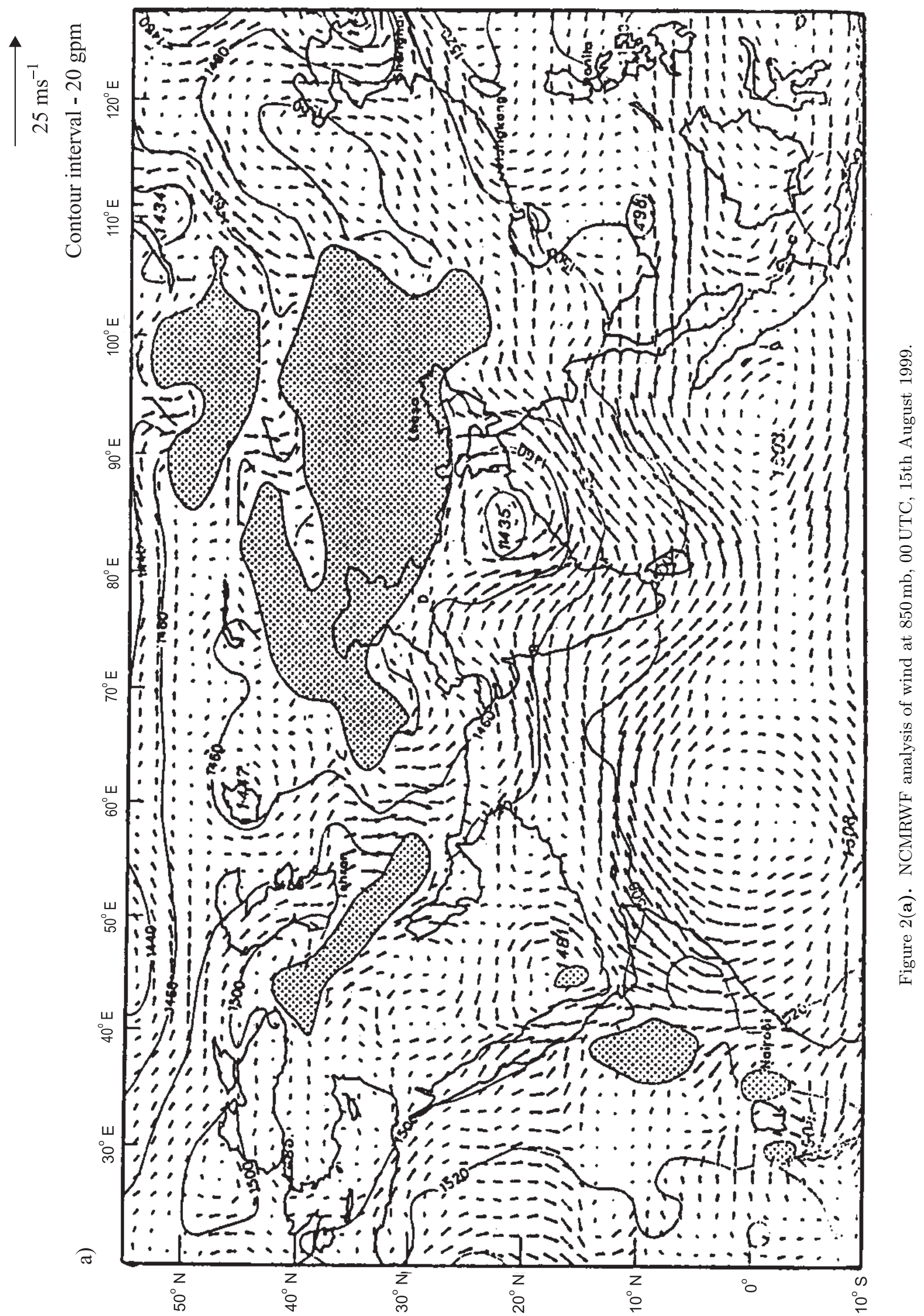




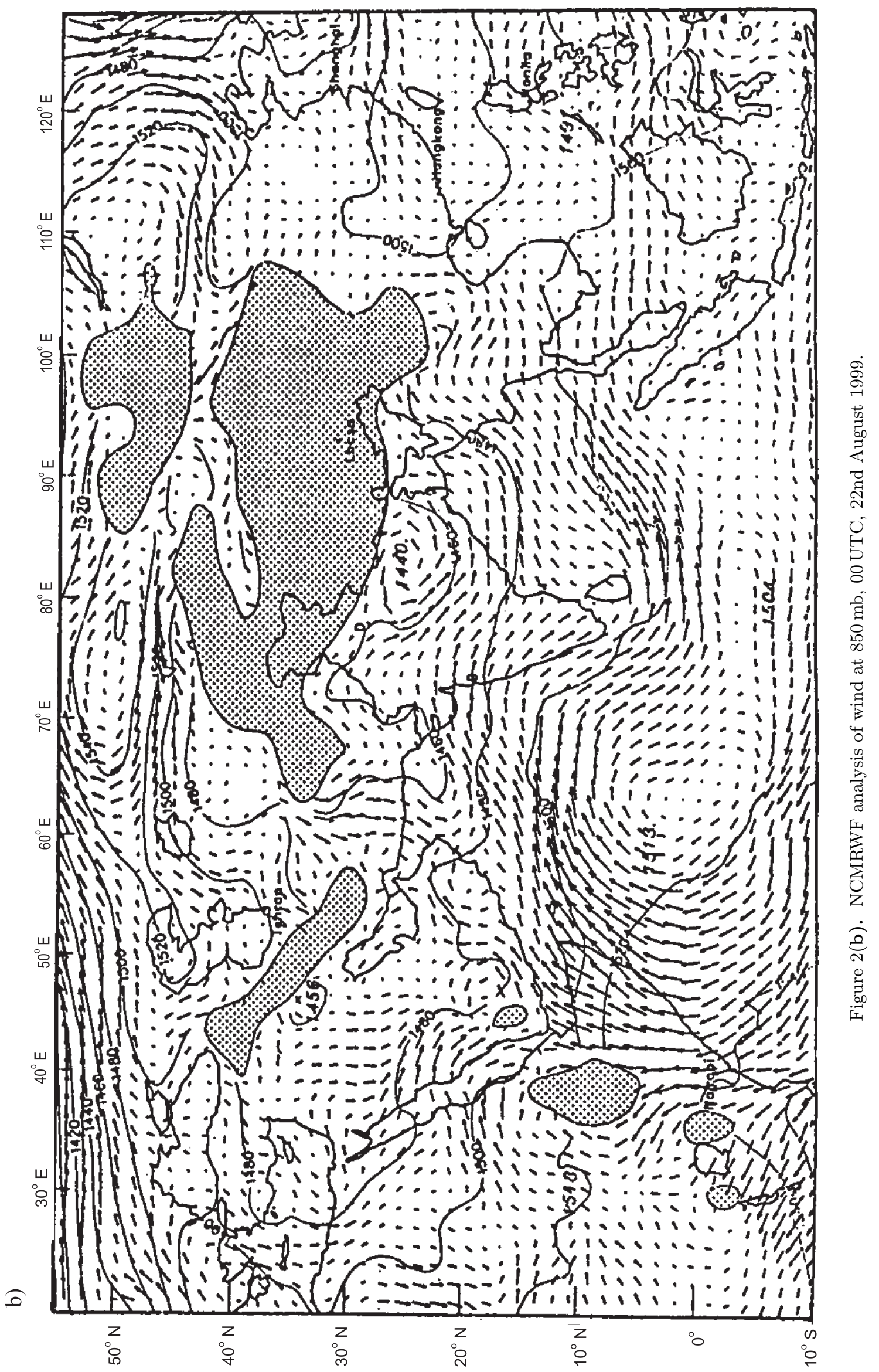



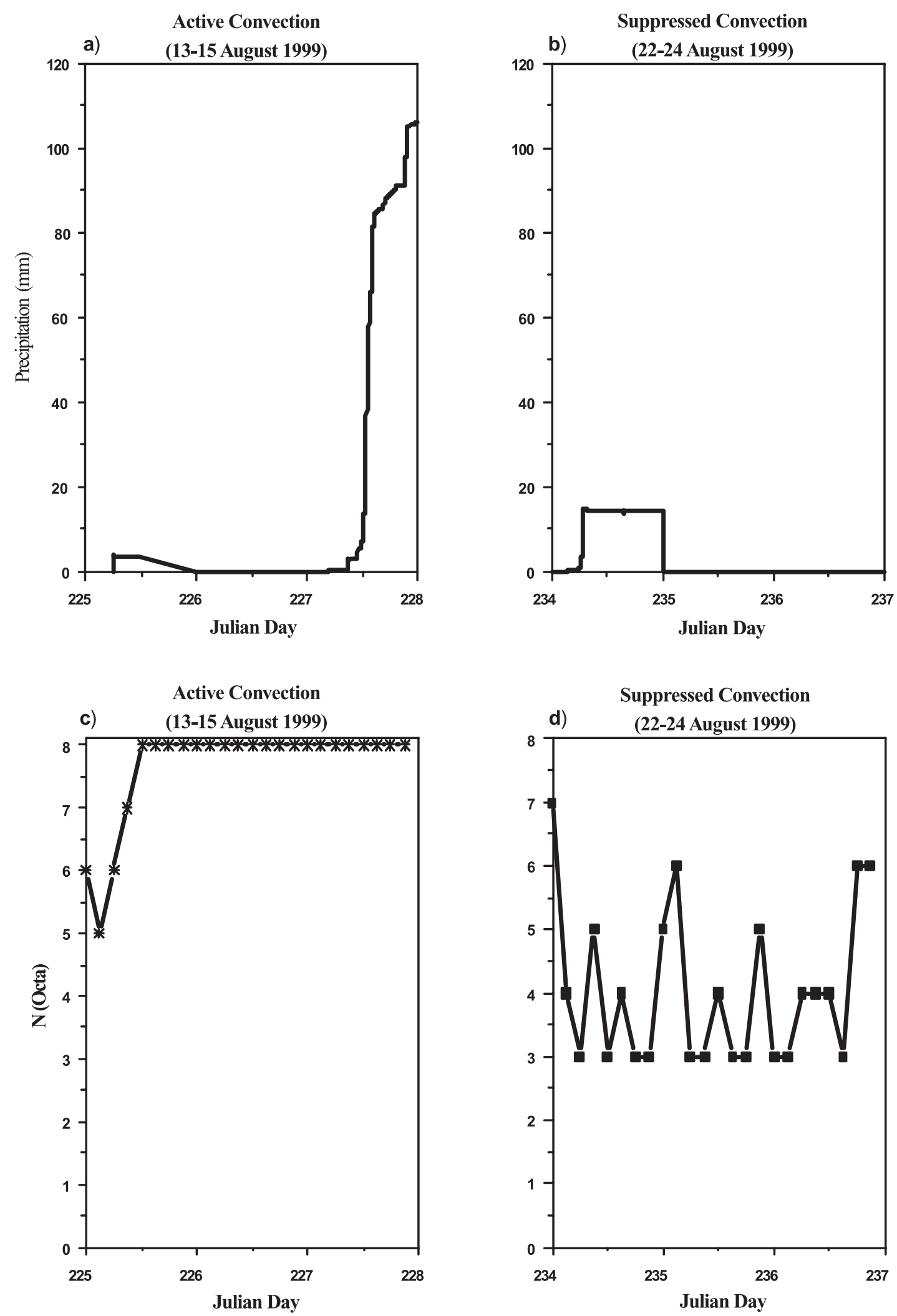

225 - 13 Aug

226 - 14 Aug

227 - 15 Aug

228 - 16 Aug

234 - 22 Aug

235 - 23 Aug

236 - 24 Aug

237 - 25 Aug

Figure 3. Precipitation amount during (a) active and (b) suppressed period; total cloud amount (N) in octa during (c) active and (d) suppressed period. 

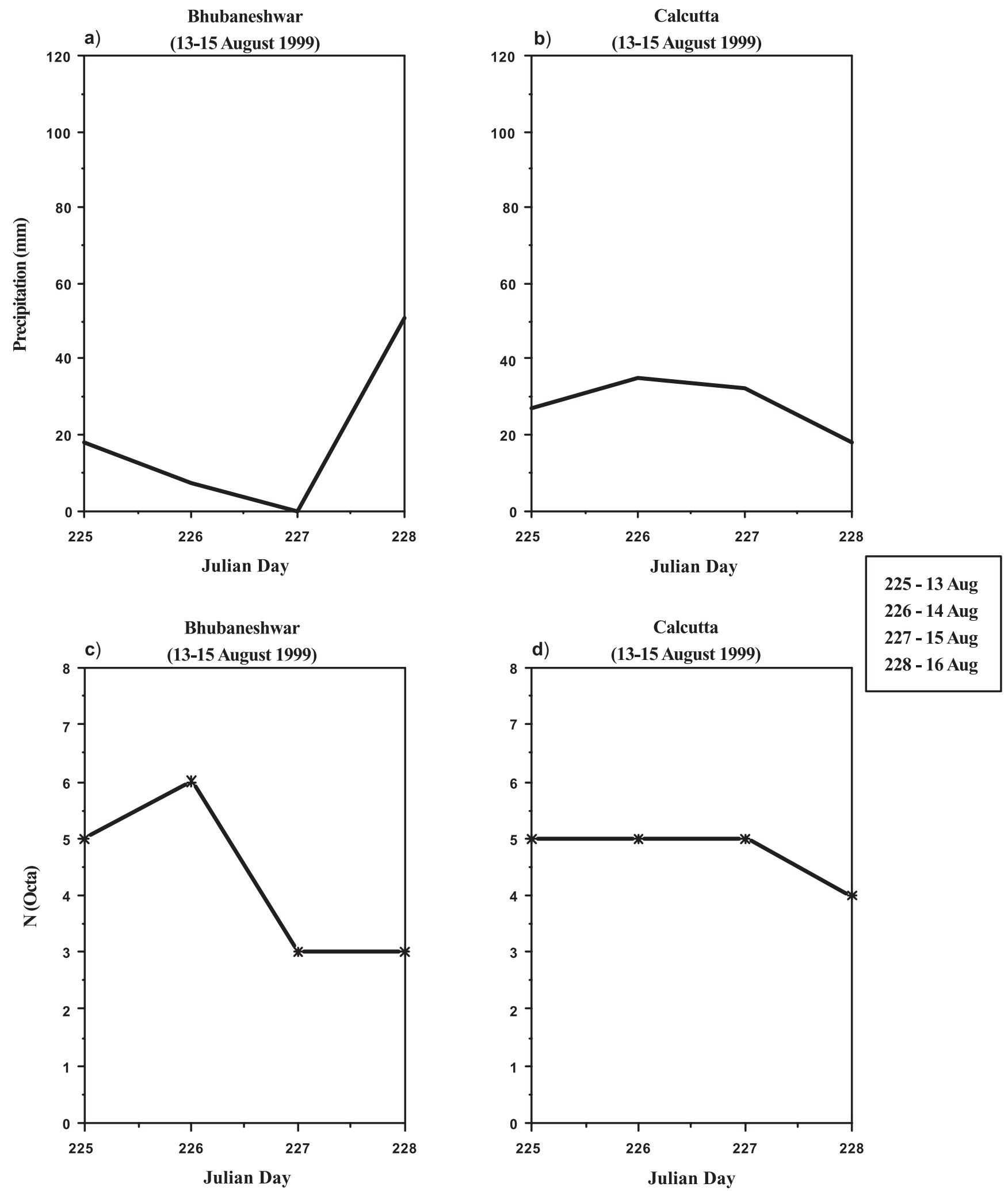

Figure 4. Precipitation amount during active period (a) at Bhubaneswar and (b) at Calcutta; total cloud amount (N) in octa during the same period (c) at Bhubaneswar and (d) at Calcutta. 


\section{Methodology}

\subsection{Vertical velocity}

The vertical velocity $(\omega)$ is calculated using the continuity equation in the $p$-coordinate system.

$$
\frac{\partial \omega}{\partial p}=-\nabla \cdot V
$$

Integrating equation (1), from pressure level $p_{1}$ to $p_{2}$ gives,

$$
\bar{\omega} p_{2}=\bar{\omega} p_{1}-\int_{p_{1}}^{p_{2}} \overline{[\nabla \cdot V]} \mathrm{d} p,
$$

where [ ] denotes layer mean. By expanding $u$ and $v$ on planar surfaces, as described below:

$$
\begin{aligned}
& u=b_{0}+b_{1}\left(t_{i}-\bar{t}\right)+b_{2}\left(x_{i}-\bar{x}\right)+b_{3}\left(y_{i}-\bar{y}\right), \\
& v=c_{0}+c_{1}\left(t_{i}-\bar{t}\right)+c_{2}\left(x_{i}-\bar{x}\right)+c_{3}\left(y_{i}-\bar{y}\right)
\end{aligned}
$$

and differentiating equation (5) and (6) with respect to $x$ and $y$, we get,

$$
\begin{aligned}
& \frac{\partial u}{\partial x}=b_{2}, \\
& \frac{\partial v}{\partial y}=b_{2} .
\end{aligned}
$$

Using (5) and (6), equation (2) can be rewritten as,

$$
\bar{\omega} p_{2}=\bar{\omega} p_{1}-\int_{p_{1}}^{p_{2}}\left[b_{2}+c_{3}\right] \mathrm{d} p
$$

where

$$
(\nabla \cdot \bar{V})_{p}=\left(\frac{\partial \bar{u}}{\partial x}\right)_{p}+\left(\frac{\partial \bar{v}}{\partial y}\right)_{p}=b_{2}+c_{3}
$$

i.e., $b_{2}$ and $c_{3}$ are the regression coefficients of $u$ and $v$ on planar surface respectively.

The boundary condition in equation (3) is chosen as,

$$
\omega_{p}=0 \text { at } p=100 \mathrm{mb}
$$

whereas, at the lower boundary vertical velocity $(\omega)$ is computed as the sum of the orographically induced vertical velocity and frictionally induced vertical motion. Thus,

$$
\omega_{1000}=-\rho_{0} g V \cdot \nabla H-\rho g \sin 2 \alpha\left[\frac{K_{v}}{2 f}\right]^{\frac{1}{2}} \nabla^{2} \psi_{0}
$$

$$
\begin{aligned}
\text { where, } & \text { kinematic eddy viscosity coefficient } \\
K_{v}= & \left(10 \mathrm{~m}^{2} \mathrm{sec}^{-1}\right), \\
\alpha= & \text { cross-isobaric flow angle }\left(22.5^{\circ}\right), \\
\psi_{0}= & \text { stream function (at } 925 \mathrm{mb}), \text { i.e., } 0.5 \\
& \left(\psi_{1000}+\psi_{850}\right), \\
H= & \text { terrain height, } \\
\rho_{0}= & \text { air density at sea-surface and } g=\text { accelera- } \\
& \text { tion due to gravity, } \\
f= & \text { coriolis parameter, }
\end{aligned}
$$

here $H=0$ (over the Bay of Bengal) and $H$ is assumed to be zero over the other two land stations for this computation.

\subsection{Divergence}

The estimation of vertical velocity is usually done by kinematic, adiabatic or vorticity technique. The technique that is used in the estimation of the vertical velocity in this paper is called the kinematic method. Here in this method, the vertical velocity is computed from equation (3), using the estimated divergence at various levels by satisfying the boundary conditions given in equations (9) and (10). One of the several reasons for the inaccuracy of the estimated values of divergence is due to errors in the wind measurement itself. The vertical velocity $\omega_{k}$ at any level $K$, then, becomes successively less acceptable as $K$ increases, due to errors in the estimation of divergence. Thus, it may not satisfy the upper boundary condition (Omotosho 1982). In order to correct this problem $\omega$ is forced to become zero at the top level. To make this possible, the error in $\omega$ at the top level is distributed linearly throughout the column assuming that the errors incurred in the estimation of divergence are equal and constant at all levels. O'Brien (1970) reasoned that if the errors are incurred in the estimation of divergence, the resulting errors in divergence should increase with the decrease in pressure. He gave a more realistic correction in the computation of vertical velocity and divergence, which, is employed in this paper.

\subsection{Convective parameters}

In the study of convection, the dry static energy $(S)$, moist static energy $(S e)$, the saturation moist static energy $(S e s)$ and the equivalent potential temperature $(\theta e)$ are very useful parameters. They are defined as follows:

$$
\begin{aligned}
S & =C_{p} T+g z, \\
S e & =C_{p} T+g z+L q, \\
S e s & =C_{p} T+g z+L q_{s}, \\
\theta_{e} & =T(1000 / p)^{R / C p} e^{L q / C p T,}
\end{aligned}
$$


where $q$ is the specific humidity and $q_{s}$ is the saturation specific humidity. The moist static energy remains conserved during both dry and moist adiabatic processes. Observed estimates of the horizontal and vertical advections of temperature and moisture may be combined with their observed temperature and moisture tendencies to produce residuals in the budgets of thermodynamic and moisture continuity equation, denoted by the apparent heat source $\left(Q_{1}\right)$ and moisture sink $\left(Q_{2}\right)$, which are defined as (Yanai et al 1973)

$$
\begin{aligned}
Q_{1} & \equiv \frac{\partial \bar{S}}{\partial t}+\bar{V} \cdot \nabla \bar{S}+\bar{\omega} \frac{\partial \bar{S}}{\partial p} \\
Q_{2} & \equiv-L\left[\frac{\partial \bar{q}}{\partial t}+\bar{V} \cdot \nabla \bar{q}+\bar{\omega} \frac{\partial \bar{q}}{\partial p}\right] .
\end{aligned}
$$

Here, $C_{p}$ is the specific heat of air at constant pressure; $V$ is the horizontal velocity, $\nabla$ the horizontal gradient operator, $\omega$ the vertical velocity, $p$ the pressure, $L$ the latent heat of condensation. The over-bar denotes a large-scale horizontal average. From $Q_{1}$ and $Q_{2}$, and estimates of surface fluxes and the radiative heating rate $\left(Q_{R}\right)$, the precipitation from a vertical column and the vertical distributions of warming and drying by cumulus clouds may be diagnosed assuming that the vertical eddy transports are primarily due to the clouds (e.g., Nitta 1972; Thompson et al 1979). $Q_{R}$ is not included in this study as its contribution to the warming/moistening is very less compared to the convective component.

\section{Results and discussion}

\subsection{Zonal and meridional wind}

The averaged profiles of zonal and meridional wind during the convectively active and suppressed periods are presented in figure 5. Westerlies prevail in the lower levels, while easterlies are present in the upper levels in both the periods (figure 5a). However, in the convectively active case the westerlies show a maximum speed of about $7.5 \mathrm{~ms}^{-1}$ at around $800 \mathrm{mb}$, while during the period of suppressed convection, maximum speed of the westerlies are found to be less than $3 \mathrm{~ms}^{-1}$. It is noticed that in both the cases, a decrease in westerlies is seen above $600 \mathrm{mb}$, which turn into easterlies, where the winds attain a maximum speed of $25 \mathrm{~ms}^{-1}$ at around $100 \mathrm{mb}$. The wind structure of this sort is typical to that noticed during the Indian summer monsoon, where the westerlies are overlain by the easterlies. Bhat et al (2002) also reported an increase in the wind speed during the convectively active period (13th-15th August 1999) at around $900 \mathrm{mb}$ level and in the upper troposphere near the $200 \mathrm{mb}$ level. Normally low winds prevailed around the $500 \mathrm{mb}$ level during both the convectively active and suppressed case. More often it leads to shear in the wind that is favourable in the development and sustenance of the convective activities (Betts 1976), in the Bay of Bengal. The vertical wind shear is not pronounced in the meridional wind (figure 5b). The diagram shows that southerly winds are in the lower levels and northerly in the upper levels above $300 \mathrm{mb}$. The observed magnitude of the meridional wind (maximum is $<9 \mathrm{~ms}^{-1}$ ) is very less compared to the zonal wind, indicating a strong zonal flow. The southward tilt of the low-pressure area during the convectively active episode causes the reversal of wind above $800 \mathrm{mb}$ in figure 5(b). Results depict that the westerlies are stronger during the convectively active period (figure $5 \mathrm{a}$ ) while the averaged profile of the meridional wind show rather weak southerly winds during the active convection period (figure 5b) and pronounced northerly winds above $300 \mathrm{mb}$ during the suppressed convection period (figure 5b). The relative reversal of meridional wind in the boundary layer below $800 \mathrm{mb}$ is a characteristic phenomenon during monsoons, when a convectively active episode is observed.

\subsection{Divergence, vorticity and vertical velocity}

The averaged profiles of divergence and vorticity fields during convectively active and suppressed conditions are shown in figure 6. Results (figure 6a) show that during the active period, there is a lowlevel mass convergence (850-750 mb), while during the suppressed period the convergence is almost ten times less. Such an increase of mass convergence over the tropical oceans leads to an increase in the convective activity. Divergence is seen at around $500 \mathrm{mb}$. Also between 300 and $100 \mathrm{mb}$ convergence is observed, which may be due to the mass out flux from the top of cumulus clouds associated with active convection. This is not prominent in suppressed conditions.

The averaged vertical profiles of vorticity during active and suppressed periods are shown in figure $6(\mathrm{~b})$. The figure shows more of positive vorticity as expected in the case of the active period and negative vorticity during the period of suppressed convection. This profile is similar to the profiles of transition from the suppressed to the disturbed period as found by Omotosho (1982).

Figure 6(c) shows the mean vertical profile of the vertical velocity during the two periods. A strong upward motion is seen throughout the atmosphere with a maximum at $500 \mathrm{mb}\left(\sim-2 \mathrm{mb} \mathrm{hr}^{-1}\right)$, and a secondary maxima is noticed near $600 \mathrm{mb}$ $\left(\sim 1.85 \mathrm{mb} \mathrm{hr}^{-1}\right)$ during the active period. A ter- 

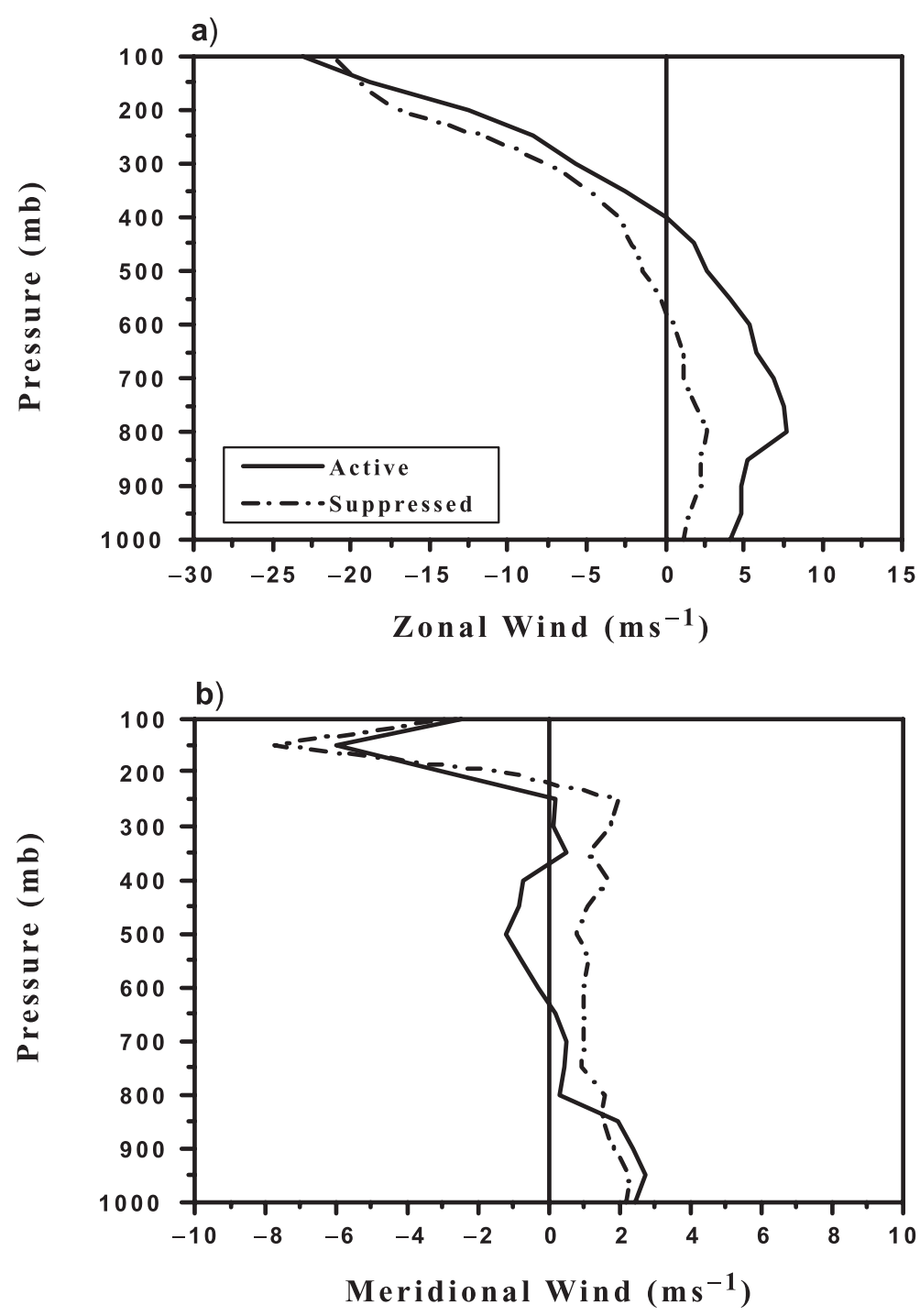

Figure 5. Averaged vertical profile of (a) zonal and (b) meridional wind during active and suppressed periods.

tiary maxima of $\sim 1.6 \mathrm{mb} \mathrm{hr}^{-1}(400-300 \mathrm{mb})$ is also seen during this period. During the suppressed period, rising motion with very low magnitude is noticed between 550 and $200 \mathrm{mb}$. Such rising motion usually leads to the formation of low pressure that may later form into a monsoon depression.

\subsection{Static energy}

Figure $7(\mathrm{a})$ and $7(\mathrm{~b})$, depict the averaged profiles of dry, moist and saturation moist static energy, during active and suppressed convection periods, while figure 7 (c) gives the difference map of all the three profiles during active and suppressed periods. An upward increasing trend from the surface noticed in the profile of the dry static energy, during the two periods is due to potential temperature and the latent heat flux. In reality, only little difference is seen in the profiles during both the periods except at some levels where the values are found to be a bit higher in the case of the disturbed period (figure 7a). The overall picture shows that the suppressed convection period (figure $7 \mathrm{~b}$ ) has slightly lower energy than the active period, throughout the atmosphere. In general, the picture of an unstable atmosphere is projected from both the profiles (figure 7a and b). A sharp increase in the moist static energy is noticed during the active period, whereas this increase is more or less gradual in case of the suppressed period. Owing to the presence of moisture in the lower atmosphere, the moist static energy is greater than the dry static energy. However, in the upper troposphere both the values approach the same. Figure 7(c) clearly depicts the increase in the moist static energy above $850 \mathrm{mb}$ till $100 \mathrm{mb}$, which confirms the transport of energy 

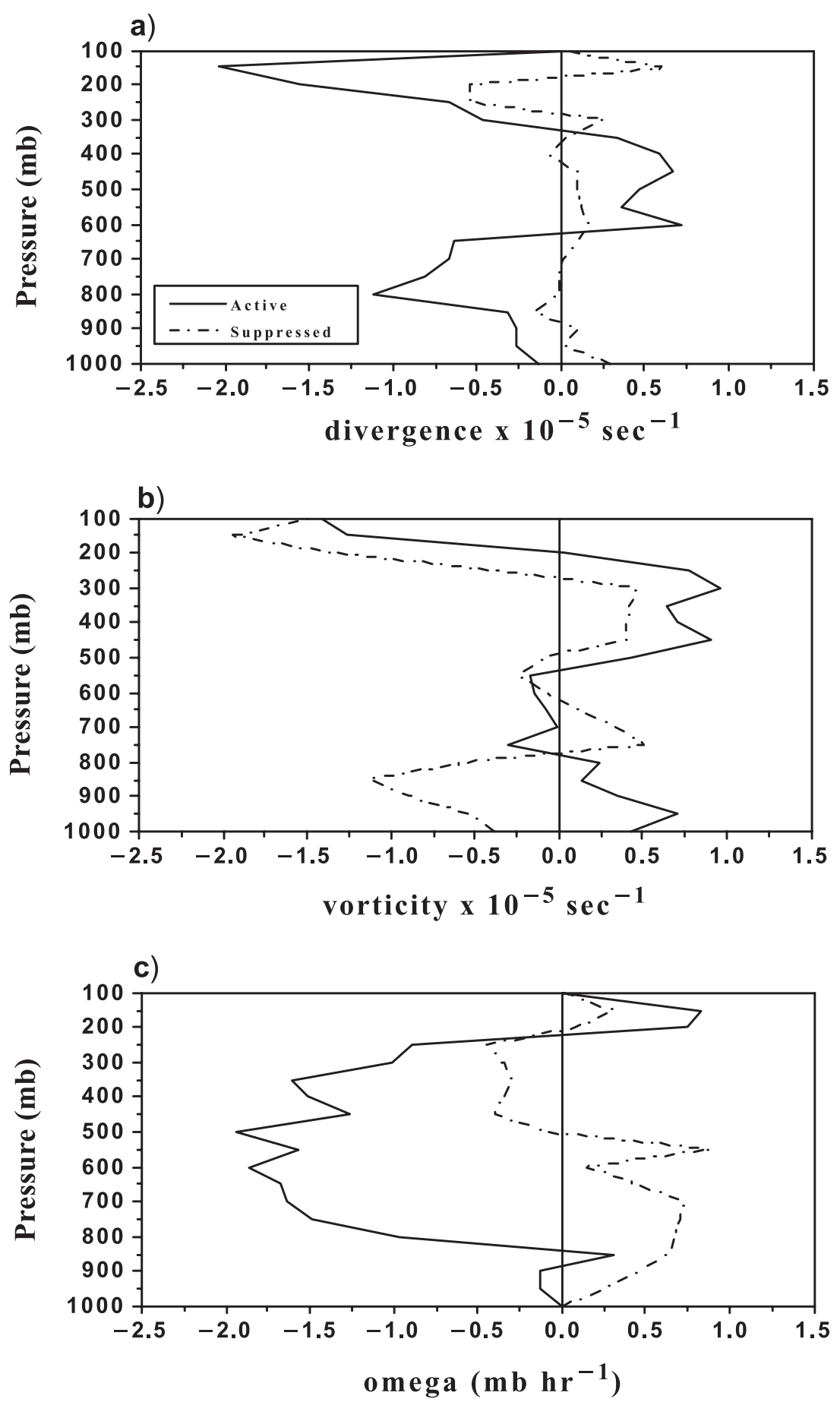

Figure 6. Averaged vertical profiles of (a) divergence, (b) vorticity and (c) omega during active and suppressed periods.

during the convective process into the higher levels. Lesser energy in the lower levels during the convectively active episode is due to cooling after the occurrence of rain.

\subsection{Apparent heat source $\left(Q_{1}\right)$ and moisture sink $\left(Q_{2}\right)$}

The daily variation and the 3-day averaged profiles of $Q_{1}$ and $Q_{2}$ during both active and sup- pressed periods of convection are respectively given in figures 8 and 9 . A continuous heating trend (between 1000 and $450 \mathrm{mb}$ ) is observed throughout the active period with pockets of maxima located around $800-700 \mathrm{mb}$ and $600-450 \mathrm{mb}$ (figure 8a). Some pockets of cooling are also seen in the lower levels below $800 \mathrm{mb}$. This cooling may be due to evaporation from the sea surface. Observations indicate that SST was above $28^{\circ} \mathrm{C}$ (Bhat et al 2001) and surface winds were of the order of 
a)

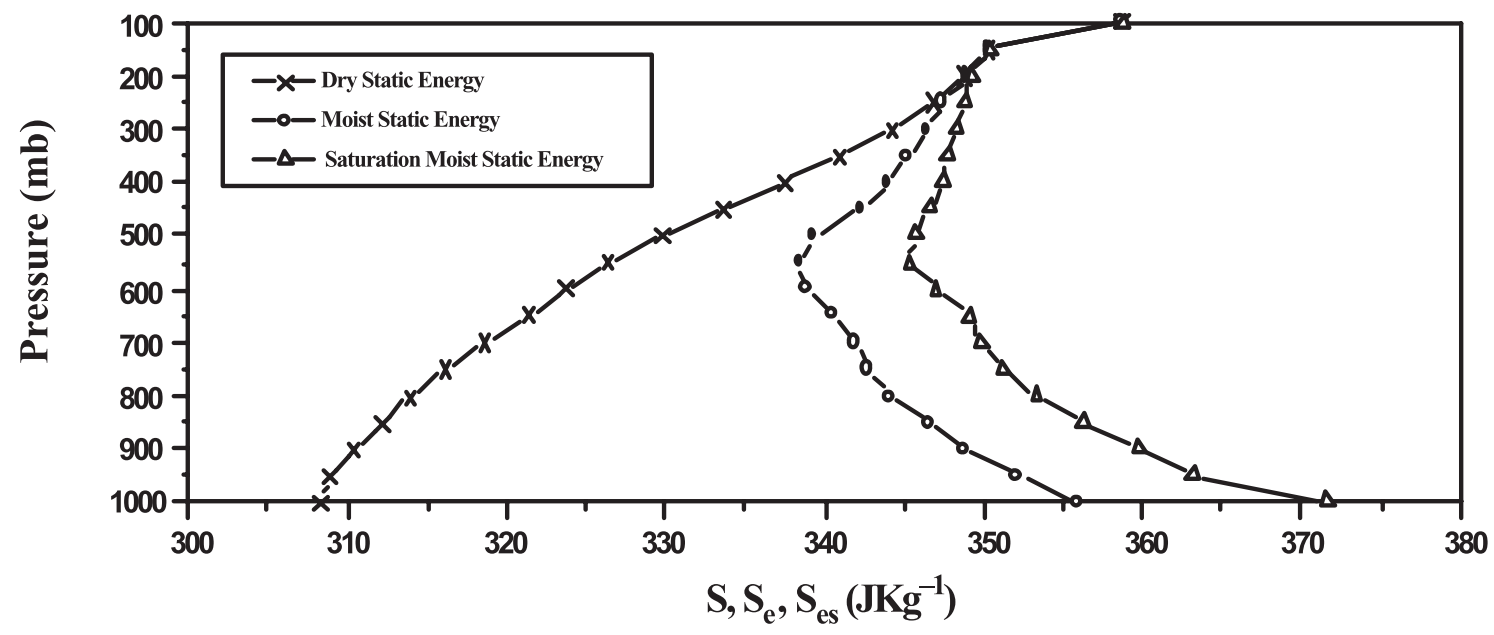

b)

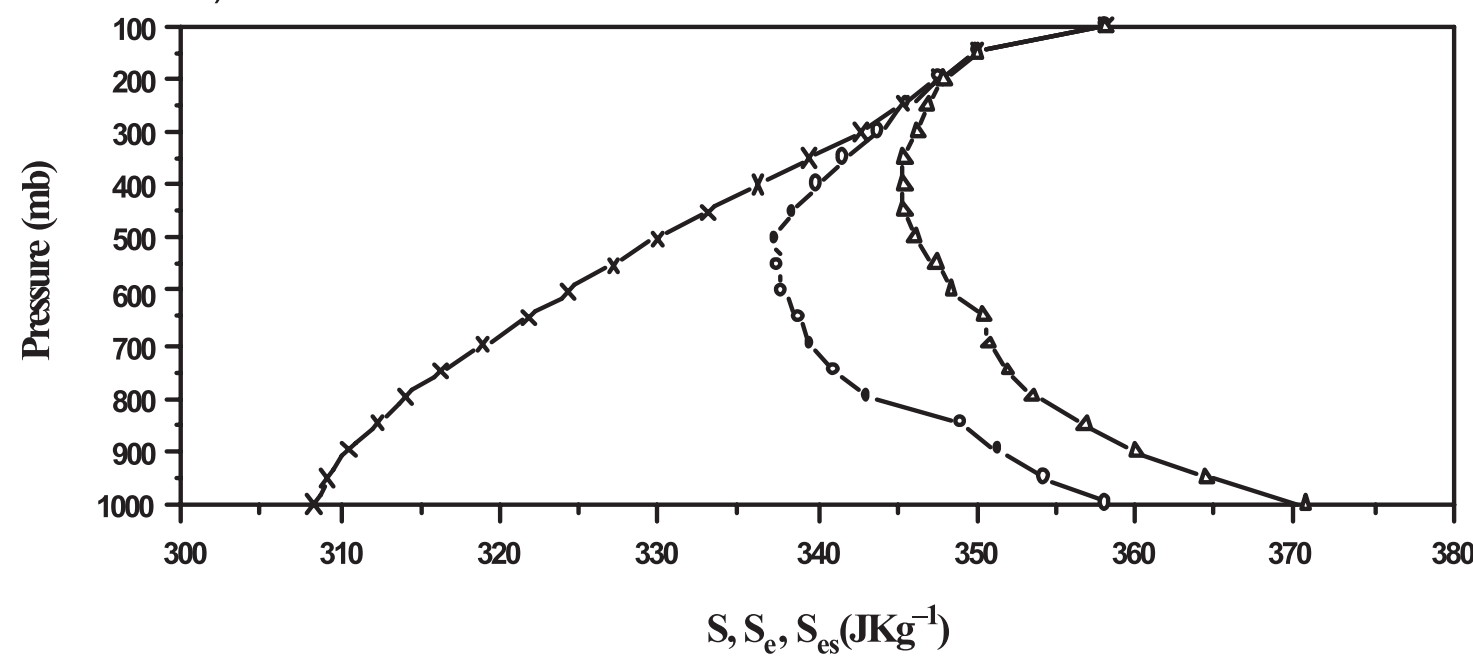

c)

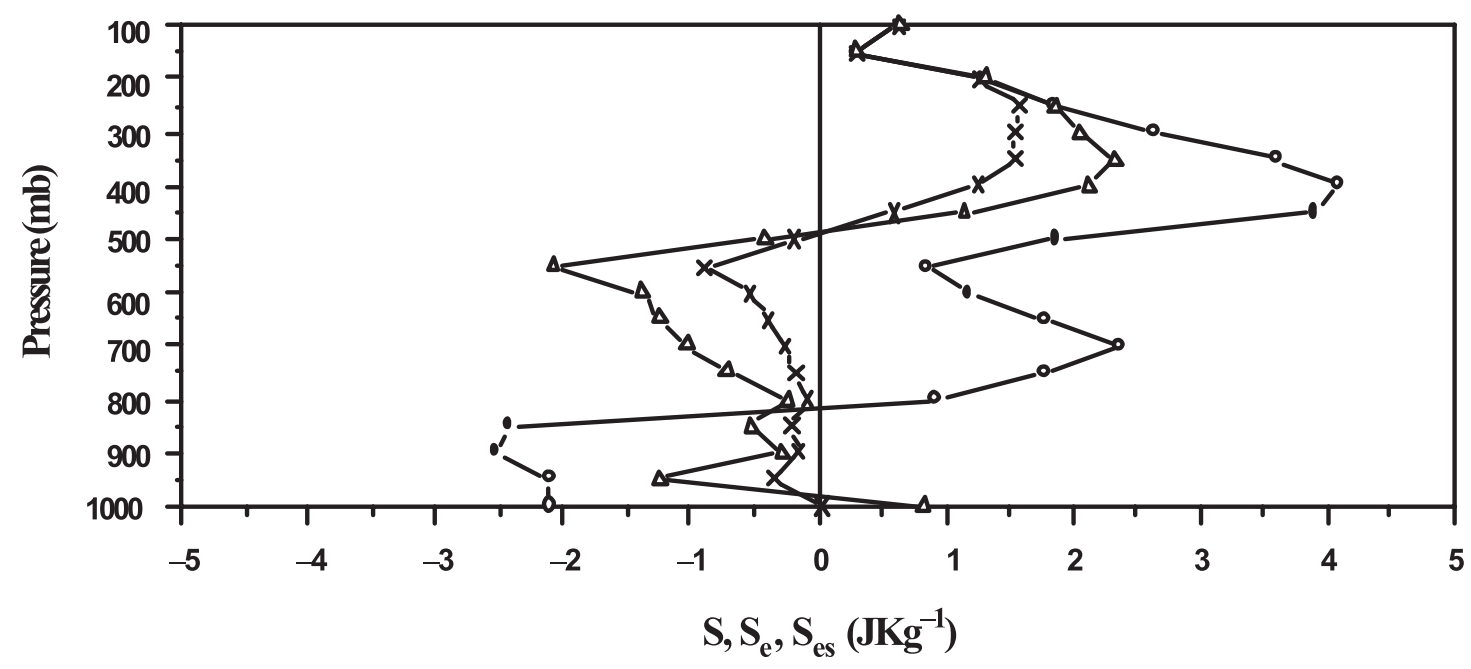

Figure 7. Dry static energy $(S)$, moist static energy (Se) and saturation moist static energy (Ses) during (a) convectively active episode, (b) suppressed convection period and (c) difference of these parameters (convective minus suppressed). 

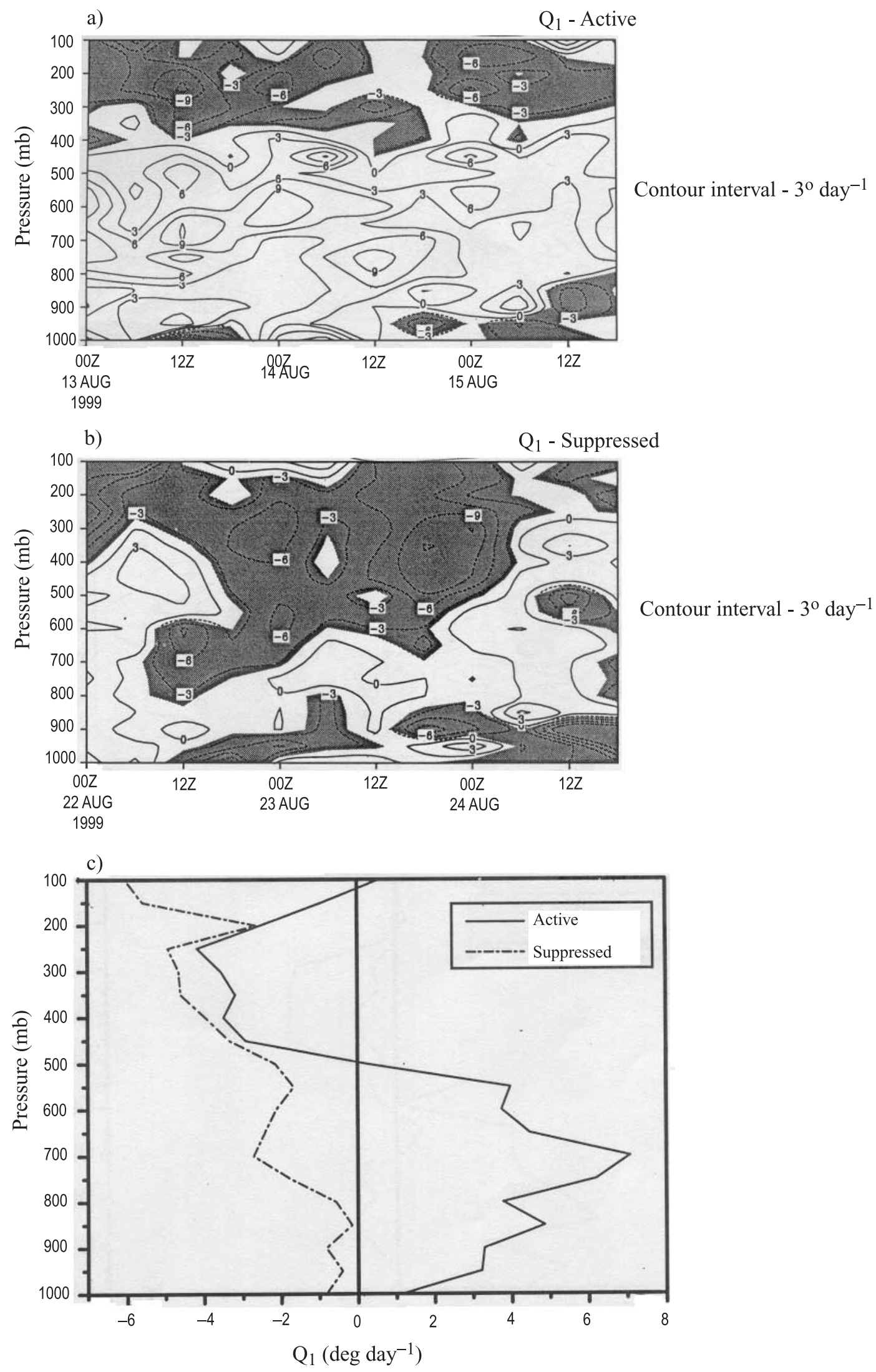

Figure 8. Daily variation of apparent heat source $Q_{1}$ during (a) active and (b) suppressed periods; (c) 3-day time averaged $Q_{1}$ during both active and suppressed periods. 

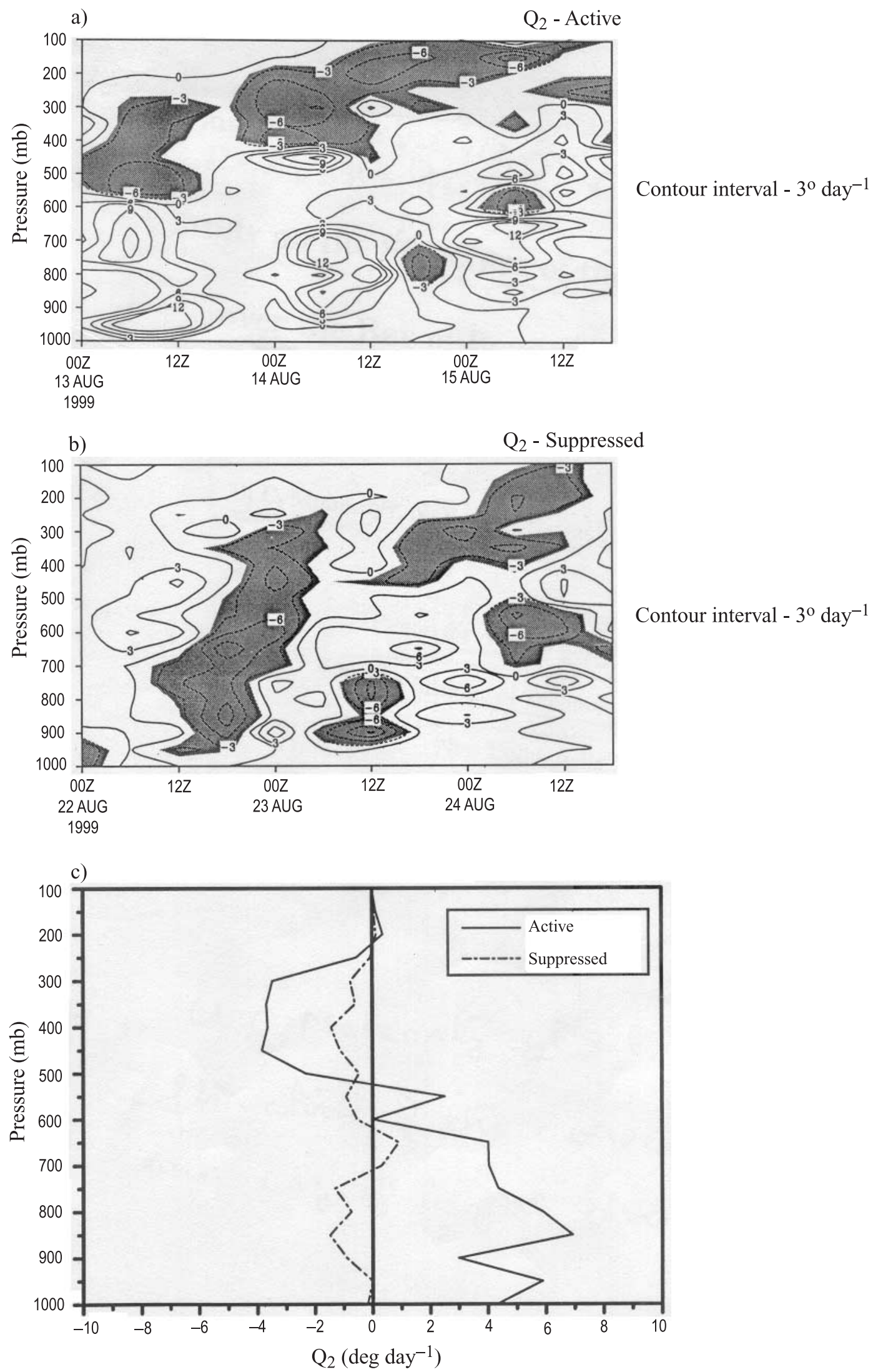

Figure 9. As in figure 8, but for the apparent moisture sink $Q_{2}$. 
$30 \mathrm{kts}$ during this period. The maximum heating rate of $12^{\circ} \mathrm{C}$ day $^{-1}$ is seen at $725 \mathrm{mb}$ level on 13 th August 1999 (12 UTC). The figure does not show any sharp change from heating to cooling between 1000 and $450 \mathrm{mb}$. The periods of maximum heating are usually associated with the passage of cloud clusters over the triangle (Krishnamurti et al 1979; Sikka and Grossman 1980; Thapilyal et al 2000). This heating may be due to the release of latent heat in cumulus clouds and its upward transport by small eddies. Associated with the active convective episode rainfall is the outcome of several processes in the atmosphere, and the most important one is the condensation of water vapour in cumulonimbus clouds (Bhat et al 2002). It is also noted that the latent heat released during condensation (an exothermic process) when a $10 \mathrm{~cm}$ rainfall is observed, corresponds to an increase in the temperature of the column of air from surface to the troposphere by more than $25^{\circ} \mathrm{C}$. A continuous cooling is seen in the upper levels above $400 \mathrm{mb}$. A maximum cooling of $10^{\circ} \mathrm{C}_{\text {day }}{ }^{-1}$ is observed at $275 \mathrm{mb}$ on 13th August 1999 (12 UTC). This cooling in the upper levels may be due to evaporation of liquid water detrained from cloud tops. The observed heating rate per day is in good agreement with the results obtained by Mohanty and Das (1986). The cooling above $250 \mathrm{mb}$ could be due to the overshooting of the rising air in cumulonimbus clouds above the level of neutral buoyancy (Ebert and Holland 1992) and radiative cooling of the cloud top.

During the suppressed convection, cooling is found to be dominant throughout the period (figure $8 \mathrm{~b}$ ). This period corresponds to warmer lower troposphere, colder mid-troposphere and a warmer layer near the tropopause, which are in agreement with the general features of tropical convection reported previously (Emmanuel 1994; Houze 1993). A maximum cooling of $-10^{\circ} \mathrm{C}$ day $^{-1}$ is observed between 300 and $200 \mathrm{mb}$ (00 UTC, 24th August 1999). However, an apparent heating of around $4{ }^{\circ} \mathrm{C}$ day ${ }^{-1}$ is seen during the first $12 \mathrm{hrs}$ and last $12 \mathrm{hrs}$ of the period between 550 and $350 \mathrm{mb}$ level. This may be due to the remnants of clouds during the transition from the convectively active to the suppressed period. A maximum cooling of $-10^{\circ} \mathrm{C}$ day $^{-1}$ is observed between 300 and $500 \mathrm{mb}$ (00 UTC, 24th August 1999). This cooling due to evaporation of moisture in the dryer atmosphere is consistent with $Q_{1}$ profile.

The time averaged vertical profile of $Q_{1}$ (figure 8c) during active convection shows a maximum heating of $7^{\circ} \mathrm{C}$ day $^{-1}$ near $700 \mathrm{mb}$. The profile of $Q_{1}$ during this period increases with height up to about $700 \mathrm{mb}$ and then decreases to two minimas of -3.75 and $-4.25^{\circ} \mathrm{C}$ day $^{-1}$ between 450 and $200 \mathrm{mb}$ respectively. In the suppressed case (figure 8c) cooling is seen throughout the vertical column. The dominant cooling effect in the period nullifies the apparent heating from some pockets in the time averaged vertical profiles.

Figure 9(a) shows heating due to apparent moisture sink $Q_{2}$ during the active period. The figure also shows that the time of maximum drying coincides with the time of maximum apparent heating. If closely observed, a diurnal pattern in the heating due to the apparent moisture sink is noticed with maximum heating between 00 and 12 UTC. Upper levels (above $600 \mathrm{mb}$ ) however, show some cooling which has a decreasing trend towards the end of the active period. The maximum value of $Q_{2}$ observed during this period is $12^{\circ} \mathrm{C}$ day $^{-1}$. During suppressed convection, negative values of $Q_{2}$ are dominant with a minimum of $-8^{\circ} \mathrm{C}$ day ${ }^{-1}$ (figure $9 \mathrm{~b}$ ). On the third day of the suppressed period, drying is seen (positive $Q_{2}$ ) in the lower levels below $700 \mathrm{mb}$. The positive value of $Q_{2}$ could be due to the presence of deep convective system developed in the northern Bay during the convectively active period (Bhat et al 2002). However, this system did not intensify further and decayed over the Bay itself.

The averaged vertical profile of $Q_{2}$ during the active and suppressed period is presented in figure 9(c). A maximum drying of $7^{\circ} \mathrm{C}$ day $^{-1}$ at $850 \mathrm{mb}$ is seen during the active period. In the suppressed period the time averaged $Q_{2}$ shows moistening throughout the column $\left(\max .-1.75^{\circ} \mathrm{C}\right.$ day $\left.^{-1}\right)$, except for some drying $\left(1^{\circ} \mathrm{C}\right.$ day $\left.^{-1}\right)$ between 700 and $600 \mathrm{mb}$. Negative values of $Q_{2}$ $\left(\sim-4^{\circ} \mathrm{C}\right.$ day $\left.^{-1}\right)$ is seen between 500 and $300 \mathrm{mb}$ during the active period. This may be due to the dryer atmosphere after evaporation at those levels. We know that clouds have tops mainly below $500 \mathrm{mb}$ and a majority of them have at around $700 \mathrm{mb}$, while atmosphere is dry above $500 \mathrm{mb}$.

\section{Summary and conclusions}

In this study we have discussed the time averaged vertical distributions of zonal and meridional wind, divergence, vorticity, vertical velocity, apparent heat source and apparent moisture sink during active and suppressed periods of convection over the Bay of Bengal during BOBMEX99. Examination of day-to-day variation in $Q_{1}$ and $Q_{2}$ together with the changes in the kinematic parameters reveals information about the interaction between convection and large-scale tropical motions.

Strong wind shear in the vertical is an important factor in the development and sustenance of mesoscale convective systems. A strong low-level 
mass convergence is observed during the convectively active period, whereas it is very less during the suppressed period. The maximum upward motion is noticed between 06 and 12 UTC that coincides with the time of maximum convergence. A general trend of warming in the lower atmosphere and pockets of cooling in the upper troposphere is seen during the active period.

The large-scale heating of the atmospheric column is primarily due to the latent heat released and during condensation adiabatic compression due to compensating downward motion in the surrounding environment. Part of the heating is also contributed by the vertical transport of heat by small eddies. The apparent heat source increases with height to a maximum value of approximately $7.5^{\circ} \mathrm{C} \mathrm{day}^{-1}$ at $725 \mathrm{mb}$. During the suppressed convection period cooling is found to be dominant, except for few pockets of heating due to the presence of stratus/stratocumulus clouds. During the active period the maximum drying by apparent moisture sink $\left(Q_{2}\right)$ due to the net condensation and vertical transport of the moisture by eddies is of the order of $7^{\circ} \mathrm{C}$ day ${ }^{-1}$. The level of maximum heating due to apparent moisture sink occurs at a relatively lower level than compared to the apparent heat source. During the suppressed convection period, the drying is relatively low as compared to the active period.

Some of the weaknesses of the present study are as follows:

- Linearly interpolated data were used so as to have continuous data sets for the present study.

- ORV Sagar Kanya is considered to be stationary, and not cruising during the period of the study, even though it was moving on $13 \mathrm{th}$ and $24 \mathrm{th}$ of August 1999.

- Incompatibility between state of observations and the scale at which convective processes operate. But this was the limitation of the BOBMEX observation.

\section{Acknowledgements}

The authors sincerely acknowledge the Council of Scientific and Industrial Research (CSIR) for providing partial financial support and the Department of Science and Technology (DST), Govt. of India for facilitating participation and obtaining BOBMEX-99 data sets. We also thank the scientific team onboard ORV Sagar Kanya, in particular Dr. G S Bhat for providing part of the BOBMEX99 data. The authors acknowledge the India Meteorological Department (IMD) for providing the surface and upper air observations from the coastal stations of India. We also thank the anonymous reviewers for their valuable comments and suggestions.

\section{References}

Betts A K 1976 Modeling subcloud layer structure and interaction with a shallow cumulus layer; J. Atmos. Sci. $\mathbf{3 3}$ $2363-2382$

Bhat G S, Gadgil S, Hareesh Kumar P V, Kalsi S R, Madhusoodan P, Murty V S N, Prasada Rao C V K, Ramesh Babu V, Rao L V G, Rao R R, Ravichandran M, Reddy K G, Sanjeeva Rao P, Sengupta D, Sikka D R, Swain J and Vinaychandran P N 2001 BOBMEX: The Bay of Bengal Monsoon Experiment; Bull. Amer. Meteor. Soc. 82 2217-2243

Bhat G S, Chakraborty A, Nanjundiah R S and Srinivasan J 2002 Vertical thermal structure of the atmosphere during active and weak phases of convection over the north Bay of Bengal: Observation and model results; Curr. Sci. $\mathbf{8 3}$ 296-302

Chang C -P 1970 Westward propagating cloud patterns in the tropical Pacific as seen from time composite satellite photographs; J. Atmos. Sci. 27 133-138

Charney J G and Eliassen A 1964 On the growth of the hurricane depression; J. Atmos. Sci. 21 68-75

DST 1996 Indian Climate Research Programme science plan. Department of Science and Technology, New Delhi, India, $186 \mathrm{pp}$.

Ebert E E and Holland G J 1992 Mon. Weather Rev. 120 $2240-2251$

Emmanuel K A 1994 Atmospheric Convection, (Oxford: Oxford University Press), pp 580

Houze R A Jr 1993 Cloud Dynamics, (New York: Academic Press) pp 572

Mohanty U C and Das S 1986 On the structure of the atmosphere during suppressed and active periods of convection over the Bay of Bengal; Proc. Indian Acad. Sci. (Earth Planet. Sci.) 52 625-640

Krishnamurti T N, Ramanathan Y, Ardanuy P and Pasch R 1979 Quick Look "Summer MONEX Atlas" Part II, the onset phase; Rep. No. 79-5, Dept. of Meteorology, Florida State University, Tallahassee, Florida.

Nitta T 1972 Energy budget of wave disturbances over the Marshall Islands during the years of 1956 and 1958; Meteorol. Soc. Jpn. $5071-84$

Nitta T 1975 Observational determination of cloud mass flux distributions; J. Atmos. Sci. 32 73-91

O' Brien J J 1970 Alternate solutions to the classical vertical velocity problem; J. Appl. Met. 9 197-203

Ogura Y and Cho H R 1973 Diagnostic determination of cumulus cloud populations from observed large-scale variables; J. Atmos. Sci. 30 1276-1286

Omotosho J A 1982 Ph D Thesis, University of Reading.

Ooyama K 1964 A dynamical model for the study of tropical cyclone development; Geofis. Intern. 4 187-198

Ooyama K 1969a Numerical simulation of the life cycle of tropical cyclones; J. Atmos. Sci. 26 3-40

Rao Y P 1976 Southwest monsoon. Synoptic meteorology; Meteorological Monogr. IMD $1367 \mathrm{pp}$.

Riehl H and Malkus J S 1958 On the heat balance in the equatorial trough zone; Geophysica 6 530-538

Riehl H and Malkus J S 1961 Some aspects of hurricane Daisy, 1958, Tellus 13 181-213

Sam N V, Mohanty U C and Satyanarayana A N V 2003 Simulation of Marine Boundary Layer characteristics using a 1-D PBL model over the Bay of Bengal during BOBMEX-99; Proc. Indian Acad. Sci. (Earth Planet. Sci.) $1122185-204$ 
Sikka D R and Grossman B 1980 Summer MONEX chronological weather summary, International MONEX Management Centre, New Delhi.

Thapliyal V, Desai D S and Krishnan V 2000 Weather in India, monsoon season (June-September 1999); Mausam $51285-318$

Thompson R M Jr, Payne S W, Recker E E and Reed R J 1979 Structures and properties of synopticscale wave disturbances in the inter-tropical conver- gence zone of the eastern Atlantic; J. Atmos. Sci. $\mathbf{3 6}$ $53-72$

Yanai M 1961a A detailed analysis of typhoon formation, $J$. Meteorol. Soc. Jpn. 39 187-214

Yanai M 1961b Dynamical aspects of typhoon formation; $J$. Meteorol. Soc. Jpn. 39 283-309

Yanai M, Esbensen S and Chu J 1973 Determination of bulk properties of tropical cloud clusters from large-scale heat and moisture budgets; J. Atmos. Sci. 30 611-627 